\title{
Alcohol calibration of tests measuring skills related to car driving
}

\author{
Stefan Jongen • Eric Vuurman • Jan Ramaekers • \\ Annemiek Vermeeren
}

Received: 9 July 2013 / Accepted: 11 December 2013 / Published online: 10 January 2014

(C) The Author(s) 2014. This article is published with open access at Springerlink.com

\begin{abstract}
Rationale Medication and illicit drugs can have detrimental side effects which impair driving performance. A drug's impairing potential should be determined by well-validated, reliable, and sensitive tests and ideally be calibrated by benchmark drugs and doses. To date, no consensus has been reached on the issue of which psychometric tests are best suited for initial screening of a drug's driving impairment potential.

Objective The aim of this alcohol calibration study is to determine which performance tests are useful to measure drug-induced impairment. The effects of alcohol are used to compare the psychometric quality between tests and as benchmark to quantify performance changes in each test associated with potentially impairing drug effects.

Methods Twenty-four healthy volunteers participated in a double-blind, four-way crossover study. Treatments were placebo and three different doses of alcohol leading to blood alcohol concentrations (BACs) of $0.2,0.5$, and $0.8 \mathrm{~g} / \mathrm{L}$.

Results Main effects of alcohol were found in most tests. Compared with placebo, performance in the Divided Attention Test (DAT) was significantly impaired after all alcohol doses and performance in the Psychomotor Vigilance Test (PVT) and the Balance Test was impaired with a BAC of 0.5 and $0.8 \mathrm{~g} / \mathrm{L}$. The largest effect sizes were found
\end{abstract}

\footnotetext{
S. Jongen $(\bowtie) \cdot$ E. Vuurman $\cdot$ J. Ramaekers $\cdot$ A. Vermeeren Experimental Psychopharmacology Unit, Faculty of Psychology and Neuroscience, Maastricht University, Maastricht, The Netherlands e-mail: stefan.jongen@maastrichtuniversity.nl

E. Vuurman

e-mail: eric.vuurman@maastrichtuniversity.nl

J. Ramaekers

e-mail: j.ramaekers@maastrichtuniversity.nl

A. Vermeeren

e-mail: a.vermeeren@maastrichtuniversity.nl
}

on postural balance with eyes open and mean reaction time in the divided attention and the psychomotor vigilance test. Conclusions The preferable tests for initial screening are the DAT and the PVT, as these tests were most sensitive to the impairing effects of alcohol and being considerably valid in assessing potential driving impairment.

Keywords Driving $\cdot$ Alcohol $\cdot$ Attention $\cdot$ Psychomotor performance $\cdot$ Cognition $\cdot$ Psychometric tests

\section{Introduction}

Many people use drugs other than alcohol (i.e., medicinal and illicit drugs) which can impair performance (e.g., Vingilis and Macdonald 2002; Walsh et al. 2004). In Europe, a study, which was a part of the DRiving Under the Influence of Drugs, alcohol and medicines (DRUID) project, reported an estimated prevalence of alcohol use of $3.48 \%$, illicit drug use of $1.90 \%$, impairing medicinal drug use of $1.36 \%$, and drugdrug combination of $0.39 \%$ in the general population of drivers (Houwing et al. 2011). A roadside survey in the USA indicated that illicit drugs are used by $5.8 \%$, medicinal drugs by $4.8 \%$, and a drug-drug combination by $0.5 \%$ of weekend drivers (Lacey et al. 2009). Because of the large number of people involved and the severity of the consequences, one of the most important risks of medicinal and illicit drug use is that of impaired driving performance and traffic accidents (e.g., O'Hanlon et al. 1982; O'Hanlon 1984; Seppala et al. 1979). Therefore, a standardized scientific evaluation of potential drug-induced performance impairment is needed to provide more meaningful warnings to users and prescribers regarding the impacts of drugs on driving (Kay and Logan 2011). In addition, there is an increasing demand from regulatory authorities to provide more information on the risks of drug-induced impairment of driving. This concerns 
not only newly developed medicinal drugs as part of the dossier for registration but also marketed and illicit drugs to determine thresholds for drug concentrations in blood associated with driving impairment (e.g., Verstraete et al. 2011).

Methodological guidelines for experimental studies assessing the effects of drugs on driving indicated that relatively simple tests may be used as a first step in screening a drug's impairment potential and that more sophisticated procedures (e.g., driving simulators, on-the-road testing) should be included in a later stage (ICADTS 1999; Kay and Logan 2011; Vermeeren et al. 1994; Walsh et al. 2008). Among the more sophisticated tests, the standardized highway driving test developed by O'Hanlon and colleagues is generally regarded as the gold standard to measure drug-induced driving impairment (O'Hanlon 1984; Verster and Roth 2011). However, no consensus has been reached on the specific tests to be used for initial screening. Such tests have to be widely available, easy to implement, and relatively cost effective. In order to provide relevant information, they should be valid with respect to measuring driving performance supported by theoretical models of driving (e.g., Michon 1989), have reasonable testretest reliability, and be sufficiently sensitive to detect druginduced impairment (Kay and Logan 2011; Walsh et al. 2008). To ensure comparability of results from various research settings, procedures should be standardized and results calibrated by benchmark drugs and doses.

The most well-known and widely used benchmark drug for assessing drug-induced driving impairment is alcohol (e.g., González-Wilhelm 2007; Louwerens et al. 1987). The increased risk of traffic accidents is well established for various legal limits of blood alcohol concentrations (BACs). Although some epidemiological studies found that the risk of being involved in a fatal crash for drivers at BACs even as low as $0.2-0.4 \mathrm{~g} / \mathrm{L}$ is increased (Zador et al. 2000), most studies found that risks increase exponentially with BACs of $0.5 \mathrm{~g} / \mathrm{L}$ and higher (e.g., Borkenstein 1964; Krüger 1993; Schnabel et al. 2010). In line with this, the legal BAC limit for driving a car is set at a BAC of $0.5 \mathrm{~g} / \mathrm{L}$ in most countries, but differences are applicable. For example, the legal limit is 0.2 and $0.8 \mathrm{~g} / \mathrm{L}$ in Sweden and the UK, respectively. Although legal limits are societal issues, it is generally agreed that the impairment produced by BACs of $0.5 \mathrm{~g} / \mathrm{L}$ and higher is clinically relevant. Therefore, a BAC of $0.5 \mathrm{~g} / \mathrm{L}$ can be used to calibrate performance changes in tests measuring drivingrelated skills. Drug effects comparable to those of alcohol with BACs between 0.5 and $0.8 \mathrm{~g} / \mathrm{L}$ are generally classified as moderately severe, whereas drug effects comparable with BACs over $0.8 \mathrm{~g} / \mathrm{L}$ are classified as severe.

Review of the literature shows that a number of psychometric tests are preferably used to assess possible driving impairment, but the choice of tests differs depending on the area of research or practice. Experimental studies assessing effects of drugs and alcohol on driving and driving-related skills in healthy volunteers concluded that tracking performance and divided attention, as measured by the Critical Tracking Test (CTT) and the Divided Attention Test (DAT), are among the most sensitive tests (e.g., Moskowitz 1973; Ramaekers et al. 2003; Robbe and O'Hanlon 1995; Verster and Roth 2011). Clinical trials assessing pharmacokinetics and pharmacodynamics of new medicinal drugs usually include the Digit Symbol Substitution Test (DSST) to determine side effects of various doses on daytime functioning (e.g., Greenblatt et al. 2006; Roth et al. 2008). In sleep research, the Psychomotor Vigilance Test (PVT) is nowadays considered as gold standard for assessing driver drowsiness resulting from disturbed or insufficient sleep (e.g., Doran et al. 2001; Jewett et al. 1999). In the field of aging and dementia, tests measuring processing speed and cognitive flexibility, such as the Trail Making Test (TMT) or the Concept Shifting Test (CST), and Digit Span Test (DST) to measure memory span, are often considered to be good predictors of on-roaddriving performance (e.g., Clark et al. 2011; Silva et al. 2009). In the field of neuropsychology, a frequent used test is the Attention Network Test (ANT) (e.g., Weaver et al. 2009), because it measures the efficiency of multiple attention networks in a relatively short time. Furthermore, balance tests as part of a Standardized Field Sobriety Test (SFST) are commonly used at the roadside by trained policemen (i.e., Drug Recognition Experts) in the USA and Australia to detect druginduced driving impairment (Stuster and Burns 1998).

The list of tests measuring driving-related and druginduced impairment is exhaustive. Therefore, not all available tests could be included; however, we aimed to compare a number of widely used tests representative for different fields of research related to driving performance and traffic safety. The main objective of this study was to compare the relative sensitivity of these tests for the dose-dependent effects of alcohol. Since the effects of alcohol are relatively nonspecific it is expected to affect performance in most tests, in particular with a BAC of $0.8 \mathrm{~g} / \mathrm{L}$. More sensitive tests and parameters are assumed to show larger effect sizes and significant effects at lower BACs. A secondary objective was to establish the mean performance changes in each test associated with three increasing doses of alcohol resulting in BACs of $0.2,0.5$, and $0.8 \mathrm{~g} / \mathrm{L}$ for future reference and interpretation of the clinical relevance of drug effects, which could provide a comparison of a full range of driving-related skills.

\section{Methods}

Participants

Twenty-five healthy male and female volunteers (ages 18 30 years) were recruited through poster advertisements at Maastricht University. Initial screening was based on a 
medical history questionnaire examined by a medical supervisor. Accepted participants underwent a physical examination, which included standard blood hematology and chemistry, urinalysis, pregnancy tests, and tests for drugs of abuse (amphetamines, benzodiazepines, cannabis, cocaine, 3,4methylenedioxymethamphetamine, and opiates). For participation, the following inclusion criteria had to be met: social drinking, defined as drinking at least three but no more than 21 glasses of alcohol, per week; and a Body Mass Index (BMI) between 19 and $29 \mathrm{~kg} / \mathrm{m}^{2}$. Exclusion criteria included pregnancy or lactation; any history of psychiatric or medical illness; history or current drug or alcohol abuse; current use of psychoactive medication; inability to stay abstinent during the study; excessive caffeine use, defined as drinking six or more cups of coffee per day; and habitual smoking, defined as smoking more than seven cigarettes a week.

One participant dropped out after the familiarization session for reasons unrelated to treatment. A total of 24 participants (12 men, 12 women) completed the study. The mean $( \pm \mathrm{SD})$ age was $22.7( \pm 2.3)$ years and their mean $( \pm \mathrm{SD}) \mathrm{BMI}$ was $22.5( \pm 2.0) \mathrm{kg} / \mathrm{m}^{2}$. The study was conducted in accordance with the code of ethics on human experimentation established by the Declaration of Helsinki (1964) and amended in Seoul (2008). All participants were informed of the study's goal, procedures, and potential hazards in writing, and they indicated their informed consent in writing. The Medical Ethics Committees of Maastricht University approved the study. Participants received a financial compensation for their participation in the study.

\section{Design and alcohol administration}

The study was conducted according to a double-blind, placebo-controlled, four-way crossover design. Treatments were alcohol doses to reach BACs of 0.0 (i.e., placebo), 0.2, 0.5 , and $0.8 \mathrm{~g} / \mathrm{L}$. Volunteers participated in two treatment days during which two doses of alcohol were administered each day. The first dose was to achieve a low BAC (i.e., 0.0 or $0.2 \mathrm{~g} / \mathrm{L}$ ) and the second dose was to achieve a high BAC (i.e., 0.5 or $0.8 \mathrm{~g} / \mathrm{L}$ ). The order of test days was balanced over participants. The washout period was at least 1 week.

The placebo dose consisted of a glass of orange juice with a small amount $(3 \mathrm{~mL})$ of alcohol floating on the surface of the beverage. This is an effective procedure which indicates that the beverage contained alcohol (e.g., Fillmore and VogelSprott 1998). In the other conditions, participants were treated with several alcohol $(97 \%)$ challenges mixed with orange juice. Alcohol was administered orally. The alcohol dosing regimen was developed to reach BACs of $0.0,0.2,0.5$, and $0.8 \mathrm{~g} / \mathrm{L}$. To verify this, breath samples were obtained with an alcohol breathalyzer (Dräger Alcotest 6510). The required quantity of alcohol to reach the aforementioned BACs depended on gender and weight of the individual. It was calculated by an improved version (Watson 1981) of the" "Widmark formula" (Widmark 1932). Within the improved formula, the amount of alcohol is related to the individual's total body water content. With consideration of the specific weight of alcohol and the BAC, the necessary quantity is calculated and divided over two glasses. Participants were allowed 5 min per glass to consume the drinks. A breath sample was obtained $10 \mathrm{~min}$ after the intake of each glass of alcohol. If necessary, an additional dose of alcohol was given to the participant. A breath sample was again obtained before testing started. Halfway the test session, the BAC was measured again, and an additional alcohol dose was administered if BAC had decreased below $0.1 \mathrm{~g} / \mathrm{L}$ of the required BAC. Figure 1 indicates a timeline of a testing day.

\section{Procedure}

Participants were individually trained to perform the behavioral tests prior to the first test day. The behavioral tests were conducted twice on two separate days. Tests were always administered according to the same order: i.e., Concept Shifting Test, Critical Tracking Test, Divided Attention Test, Psychomotor Vigilance Test, Digit Symbol Substitution Test, Digit Span Test, Attention Network Test, and Postural Balance Test.

During participation in the study, alcohol intake was not allowed from $24 \mathrm{~h}$ prior to each dosing until discharge. On treatment days, caffeine intake and smoking were not allowed until discharge. Participants agreed not to use any drugs of abuse or oral medication (except oral contraceptives and aspirin) during the study.

On treatment days, participants fasted for $4 \mathrm{~h}$ before arrival at the lab. Participants yielded urine and breath samples prior to each test session to confirm their compliance with prohibitions against prior use of drugs and to verify a BAC of $0.0 \mathrm{~g} / \mathrm{L}$ at the beginning of each session. Urine samples of women were examined to exclude pregnancy. A testing day ended at 2100 hours at which time participants were driven home.

\section{Assessment}

\section{Critical Tracking Test}

The Critical Tracking Test (CTT) measures the ability to control an unstable error signal in a first-order compensatory tracking task (Jex et al. 1966). This test is designed to measure psychomotor coordination. Tracking skills are especially important at the operational/control level of driving behavior (e.g., keeping the car in a steady position within the lane). Participants are instructed to keep an unstable bar in the middle of a horizontal plane by counteracting or reverse its movements with the aid of a joystick. The frequency of cursor deviations at which the participant loses control is the critical 
Fig. 1 Timeline in minutes for alcohol administration, test performance, and obtaining BAC samples

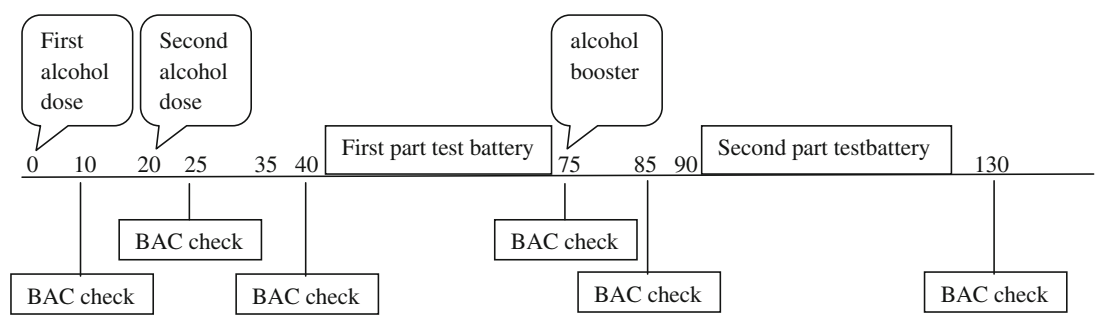

frequency or lambda $\left(\lambda_{c}\right.$, in rad/s). The final score is determined from the average of all but the lowest and highest scores in five trails. Total duration of the test is approximately $3 \mathrm{~min}$.

\section{Divided Attention Test}

The Divided Attention Test (DAT) measures the ability to perform two tasks simultaneously (Moskowitz 1973). In the primary task, the participants perform the same tracking task described above, set at a constant level of difficulty. In the other task, the participant monitors 24 peripheral displays in which single digits change asynchronously at 5 -s intervals. Participants are instructed to remove their foot from a pedal as rapidly as possible whenever the digit " 2 " appears. This signal occurs twice at every location, in random order, at intervals of 5-25 s. Tracking error (DAT-ER, in $\mathrm{mm}$ ) and average reaction time to targets (DAT-RT, in ms) are the respective performance measures. Duration of the task is $12 \mathrm{~min}$.

\section{Psychomotor Vigilance Test}

The Psychomotor Vigilance Test (PVT) is based on a simple visual reaction time test (Dinges and Powell 1985). The test measures ability to sustain attention over a period of $10 \mathrm{~min}$. Participants are required to respond to a visual stimulus presented at a variable interval (2,000 to $10,000 \mathrm{~ms})$ by pressing a button with the dominant hand. The visual stimulus is a counter turning on and incrementing from 0 to $60 \mathrm{~s}$ at $1-\mathrm{ms}$ intervals. If a response has not been made in $60 \mathrm{~s}$, the clock resets and the counter restarts. The reciprocal transform of the reaction time (1/RT) was calculated because it emphasizes slowing in the optimum and intermediate response domain and substantially decreases the contribution of long lapses. For calculation of mean 1/RT, each RT (ms) was divided by 1,000 and then reciprocally transformed. This measure has shown to indicate the largest effect sizes when taking mean reaction times into account (Basner and Dinges 2011).

\section{Attention Network Test}

The Attention Network Test (ANT) provides measures of three functions of attention within a single task: alertness, orienting, and executive control (Fan et al. 2002). Each trial begins with the presentation of a fixation cross in the middle of the computer screen. Participants are instructed to keep their eyes fixated on the cross throughout the test. Then, at some variable interval (ranging from 400 to $1,600 \mathrm{~ms}$ ), a cue is presented for $100 \mathrm{~ms}$. Four hundred milliseconds after the offset of the cue, a target display appears and remains until response (i.e., a key-press indicating the direction of the target arrow), or for $1,700 \mathrm{~ms}$ if no response is made. The interstimulus interval is $3,500 \mathrm{~ms}$. There are four cue conditions and three target conditions. Targets (neutral, congruent, or incongruent) can appear either above or below the fixation cross. Dependent variables are total reaction time (RT) and differences between RTs reflecting efficiency of alerting (RT no cue-RT double cue), orienting (RT center cue-RT spatial cue), and executive networks (RT incongruent flankers-RT congruent flankers). Duration of the test is approximately $25 \mathrm{~min}$.

\section{Digit Symbol Substitution Test}

The Digit Symbol Substitution Test (DSST) measures many different psychomotor and cognitive functions at the same time (Riedel et al. 2006). A computerized version of the original paper-and-pencil test (McLeod et al. 1982) taken from the Wechsler Adult Intelligence Scale is used (e.g., Leufkens et al. 2009). The participant is required to match each digit with a symbol from the encoding list as rapidly as possible by clicking the corresponding response button, using the mouse. The number of digits encoded correctly within $3 \mathrm{~min}$ is the performance measure.

\section{Concept Shifting Test}

The computerized Concept Shifting Test (CST) is used to measure processing speed and cognitive flexibility (Van der Elst et al. 2006). It consists of three subtasks (A, B, and C). On each display, 16 small circles are grouped into one larger circle. In the smaller circles, the test items appear in a fixed random order. Participants are asked to cross out numbers (116 ) in the right order as quickly and accurately as possible, using a touch screen. In part B, the circles contain letters (AP) that have to be crossed out in alphabetical order. In part C, both numbers and letters are displayed, and the participant is requested to alternate between numbers and letters. The time needed to complete each part is scored in seconds (CST-A, CST-B, and CST-C, respectively). An interference score 
$\left(\mathrm{CST}_{\mathrm{i}}\right)$ was obtained by the following formula: (CST-C $-1 / 2 \times($ CST-A + CST-B $)) /(1 / 2 \times($ CST-A + CST-B $)) \times 100$. Total duration of the test is approximately $3 \mathrm{~min}$.

\section{Digit Span Test}

The Digit Span Test (DST) measures memory span. It consists of two parts: one for forward digit span and one for backward digit span. In the forward part of the DST (Wechsler 1997), the experimenter reads various series of digits, $1-9$, to the participant. The series are increased in length by one digit from trial to trial. Two sequences are presented for each span size. The instruction is to remember the digits and recall them immediately in correct serial order. Testing stops when the participant makes a mistake in both trials of the same span length. In the backward part of the DST, sequences of numbers are read out to participants who are asked to repeat them, in reverse order. The number of sequences correctly recalled forward and backward is recorded (DST-FW, DST-BW). Total duration of the test is approximately $2 \mathrm{~min}$.

\section{Postural Balance Test}

The Postural Balance Test (PBT) measures the participant's ability to maintain balance while standing upright on both feet. Balance is measured using the AMTI AccuSway System for Balance and Postural Sway Measurement (Advanced Mechanical Technology, Inc., Watertown, MA, USA) force platform (Mets et al. 2010, 2011). Postural sway is assessed by measuring the length of the path of the center of pressure (COP) and the area of the $95 \%$ confidence ellipse enclosing the COP (A95). The test is conducted in two trials of both $60 \mathrm{~s}$ : one trial with the participants' eyes open and one trial with eyes closed, both with feet apart at the hip's width.

\section{Subjective measures}

Participants had to describe their subjective feeling in three dimensions (i.e., alertness, contentedness, and calmness) by using 16 Visual Analogue Scales (VAS) (Bond and Lader 1974). An additional scale was added on which participants could indicate their perceived degrees of intoxication. All scales were administered twice: once before testing started in a treatment condition and once afterward. After a testing day, participants were asked to estimate their level of intoxication (i.e., a BAC of $0.0,0.2,0.5$, or $0.8 \mathrm{~g} / \mathrm{L}$ ) by a fixed choice question (i.e., "which BAC do you think we aimed to reach?") for both test sessions.

Statistical analyses

Sample size calculation was based on detecting a minimally relevant difference with an effect size of 0.25 between placebo and the $0.5 \mathrm{~g} / \mathrm{L}$ BAC condition. Given a test-retest reliability of tracking error and reaction time at the Divided Attention Test of at least $r=0.75$ (Ramaekers et al. 2011a), a group of 24 participants should permit detection of a mean change in tracking error and reaction time, with a power of at least $90 \%$ and an $\alpha$ of 0.05 .

First, correlations between the dependent variables from the eight tests in the placebo condition were calculated to determine differences or similarities in cognitive processes measured by each parameter.

Second, alcohol effects on each parameter were analyzed using general linear model repeated measures with alcohol (4 levels) as within-subjects factor. Three separate alcoholplacebo contrasts were conducted when an overall effect of alcohol was found. Bonferroni adjustment for the number of tests has been applied to correct for multiple comparisons $(\alpha=$ $0.05 / 3=0.0167$ ).

Third, difference scores from placebo were calculated for the three active alcohol conditions to determine mean changes and $95 \%$ confidence intervals for each parameter and alcohol dose.

Fourth, change scores for each of the dependent variables were transformed to $z$-scores, which were calculated across the pooled changes in the three active alcohol conditions. This allows for easy comparison across each of the various performance tests (Dry et al. 2012).

Finally, effect sizes were calculated to determine the magnitude of the effects of alcohol, using the effect size (ES) statistic (i.e., $t_{\mathrm{c}}[2(1-r) / n]^{1 / 2}$ ) for repeated measures of Dunlap et al. (1996). ESs between 0 and 0.2 are considered small, between 0.2 and 0.7 are considered moderate, and 0.7 or higher are considered large (Falleti et al. 2003). All statistical analyses were done by using the Statistical Package for the Social Sciences for Windows (version 19; SPSS Inc, Chicago, IL, USA).

\section{Results}

\section{Missing data}

Due to technical problems, no data were collected during the DAT on two occasions and during the CST on a single occasion. Only participants with complete data sets were entered into the analysis of the respective performance parameter.

\section{Blood alcohol concentrations}

Figure 2 shows participants' mean BAC at each interval when breath samples were obtained. Participants' BAC generally peaked in the ranges of $0.16-0.27 \mathrm{~g} / \mathrm{L}$ (mean $\pm \mathrm{SD}, 0.22 \pm$ $0.03 \mathrm{~g} / \mathrm{L}), 0.45-0.56 \mathrm{~g} / \mathrm{L}(0.51 \pm 0.04 \mathrm{~g} / \mathrm{L})$, and $0.70-1.03 \mathrm{~g} / \mathrm{L}$ $(0.78 \pm 0.07 \mathrm{~g} / \mathrm{L})$ within $40 \mathrm{~min}$ after drinking in the conditions to reach a BAC of $0.2,0.5$, and $0.8 \mathrm{~g} / \mathrm{L}$, respectively. 


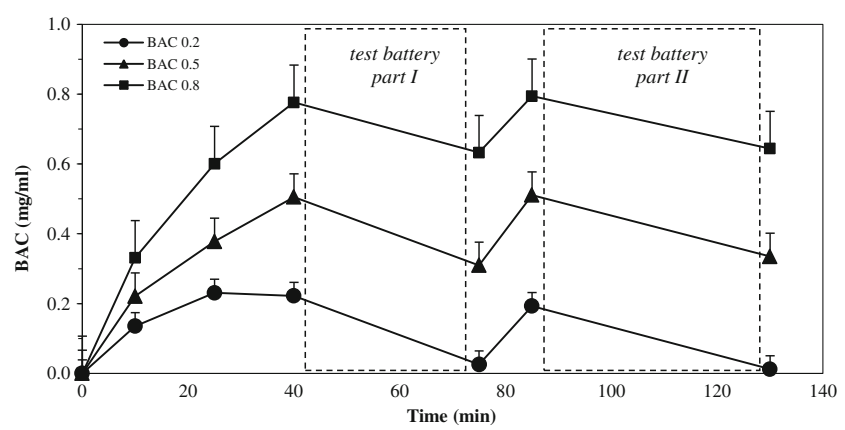

Fig. 2 Mean blood alcohol concentrations $(B A C)$ at each interval when breath samples were obtained. Capped vertical lines show standard errors of the mean

Mean BAC declined to $0.03,0.31$, and $0.63 \mathrm{~g} / \mathrm{L}$, respectively, over the course of the next $45 \mathrm{~min}$. Booster doses were then administered to participants in whom the BAC reached below $0.1 \mathrm{~g} / \mathrm{L}$ of the appropriate $\mathrm{BAC}$. Mean BACs of $0.19 \pm 0.04,0.51 \pm 0.04$, and $0.79 \pm 0.06 \mathrm{~g} / \mathrm{L}$ were achieved $10 \mathrm{~min}$ later, and participants finished testing 45 min later with $0.01 \pm 0.03,0.34 \pm 0.05$, and $0.64 \pm$ $0.05 \mathrm{~g} / \mathrm{L}$, respectively.

\section{Correlations of performance measures}

Correlations between the dependent variables from the eight tests measured in the placebo conditions showed that most correlations were low and not significant $(-0.4 \leq r \leq 0.4)$. Absolute values of eight correlations were moderate (i.e., varying between 0.41 and 0.57 ). Performance in the PVT and DSST each correlated with performance in three other tests. Both correlated with overall reaction time in the ANT ( $r=0.45$ and $r=-0.46$, respectively). In addition, performance in the PVT correlated with tracking performance in the DAT $(r=0.49)$ and in the CTT $(r=0.48)$. Performance in the DSST, on the other hand, correlated additionally with reaction time in the DAT (i.e., target detection, $r=0.52$ ) and with DST-forward $(r=0.46)$. Finally, tracking performance in the CTT correlated with tracking error in the DAT $(r=-0.41)$, and the highest correlation was found between DST-forward and DSTbackward $(r=0.57)$.

\section{Alcohol effects}

Table 1 presents a summary of the means and standard errors of the means (SE) of all performance scores and the results of the analyses of variance.

A main effect of alcohol was found in tracking performance at the CTT $\left(F_{3,21}=5.40, p<0.01\right)$. Contrast analysis revealed a decrease of tracking performance with a BAC of $0.2 \mathrm{~g} / \mathrm{L}\left(F_{1,23}=6.26, p<0.05\right)$ and $0.8 \mathrm{~g} / \mathrm{L}\left(F_{1,23}=17.57\right.$, $p<0.001)$ compared with placebo. A main effect of alcohol was found for reaction time at the DAT $\left(F_{3,19}=5.71, p<0.01\right)$.
Contrast analysis indicated that this effect on reaction time was due to all three active alcohol conditions: with a BAC of $0.2 \mathrm{~g} / \mathrm{L}\left(F_{1,21}=4.40, p<0.05\right), 0.5 \mathrm{~g} / \mathrm{L}\left(F_{1,21}=9.53, p<0.01\right)$, and $0.8 \mathrm{~g} / \mathrm{L}\left(F_{1,21}=16.47, p=0.001\right)$ compared with placebo. For tracking error, a trend was found $\left(F_{3,21}=2.70, p=0.07\right)$.

The inverse reaction time (1/RT) at the PVT significantly differed between alcohol conditions $\left(F_{3,21}=5.74, p<0.01\right)$. Contrast analysis indicated that this effect was due to both the BACs of $0.5 \mathrm{~g} / \mathrm{L}\left(F_{1,23}=8.46, p<0.01\right)$ and $0.8 \mathrm{~g} / \mathrm{L}\left(F_{1,23}=\right.$ $14.12, p=0.001)$ compared with placebo. Reaction time at the ANT differed between alcohol conditions $\left(F_{3,21}=9.93\right.$, $p<0.001)$. Reaction time increased with a BAC of $0.8 \mathrm{~g} / \mathrm{L}$ $\left(F_{1,23}=19.11, p<0.01\right)$ as compared with placebo. No main effects of alcohol were found at the three different networks.

A main effect of alcohol was found for correct responses at the DSST $\left(F_{3,21}=11.12, p<0.001\right)$. Participants' correct responses decreased significantly with a BAC of $0.8 \mathrm{~g} / \mathrm{L}\left(F_{1,23}=\right.$ $8.32, p<0.01)$ compared with placebo.

In the PBT, values of the A95 were not normally distributed and therefore natural log-transformed (e.g., Boyle et al. 2009). Main effects of alcohol were found in both the eyes open $\left(F_{3,21}=14.12, p<0.001\right)$ and eyes closed condition $\left(F_{3,21}=\right.$ $6.53, p<0.01)$. In the eyes open condition, contrast analysis indicated a trend of A95 with a BAC of $0.2 \mathrm{~g} / \mathrm{L}\left(F_{3,21}=3.52\right.$, $p=0.07)$ and simple effects with a BAC of $0.5 \mathrm{~g} / \mathrm{L}\left(F_{1,23}=\right.$ $13.33, p=0.001)$ and $0.8 \mathrm{~g} / \mathrm{L}\left(F_{1,23}=45.74, p<0.001\right) \mathrm{com}$ pared with placebo. In the eyes closed condition, simple effects were found with a BAC of $0.5 \mathrm{~g} / \mathrm{L}\left(F_{1,23}=15.15, p=\right.$ $0.001)$ and $0.8 \mathrm{~g} / \mathrm{L}\left(F_{1,23}=12.84, p<0.01\right)$ compared with placebo.

No main effects of alcohol were found at the three subtests of the Concept Shifting Test (i.e., CST-A, CST-B, and CST-C) and the interference score and at the two subtests of Digit Span Test (i.e., forward and backward).

\section{Subjective evaluations}

Participants' ratings of intoxication as measured by two VAS (i.e., before and after the test battery) differed between alcohol conditions both before $\left(F_{3,21}=28.49, p<0.001\right)$ and after $\left(F_{3,21}=20.77, p<0.001\right)$ testing. Simple contrasts indicated that participants felt more intoxicated before testing with a BAC of $0.2 \mathrm{~g} / \mathrm{L}\left(F_{1,23}=17.05, p<0.001\right), 0.5 \mathrm{~g} / \mathrm{L}\left(F_{1,23}=\right.$ $52.53, p<0.001)$, and $0.8 \mathrm{~g} / \mathrm{L}\left(F_{1,23}=81.92, p<0.001\right)$ compared with placebo. Simple contrasts indicated that participants felt more intoxicated after testing with a BAC of $0.2 \mathrm{~g} / \mathrm{L}$ $\left(F_{1,23}=13.57, p \leq 0.001\right), 0.5 \mathrm{~g} / \mathrm{L}\left(F_{1,23}=53.56, p \leq 0.001\right)$, and $0.8 \mathrm{~g} / \mathrm{L}\left(F_{1,23}=59.03, p \leq 0.001\right)$ compared with placebo (see Fig. $4 \mathrm{~d}$ for an average of both scales). Participants' ratings of alertness differed significantly between BAC conditions $\left(F_{3,21}=11.86, p<0.001\right)$. Participants indicated decreased alertness in the $0.8 \mathrm{~g} / \mathrm{L}$ condition $\left(F_{1,23}=13.85, p=0.001\right)$ as compared with placebo. No main effects of alcohol were 
Table 1 Mean (SE), overall treatment effects, and contrast analyses of performance tests

\begin{tabular}{|c|c|c|c|c|c|c|c|c|c|}
\hline \multirow[t]{3}{*}{ Test } & \multicolumn{4}{|l|}{ Mean (SE) } & \multicolumn{2}{|c|}{ Overall treatment effect } & \multicolumn{3}{|c|}{ Simple contrast analysis } \\
\hline & \multirow[b]{2}{*}{ PLA } & \multirow[b]{2}{*}{$0.2 \mathrm{~g} / \mathrm{L}$} & \multirow[b]{2}{*}{$0.5 \mathrm{~g} / \mathrm{L}$} & \multirow[b]{2}{*}{$0.8 \mathrm{~g} / \mathrm{L}$} & \multirow[b]{2}{*}{$F$} & \multirow[b]{2}{*}{$p$} & \multirow{2}{*}{$\begin{array}{l}\text { PLA versus } \\
0.2 \mathrm{~g} / \mathrm{L} \\
p\end{array}$} & \multirow{2}{*}{$\begin{array}{l}\text { PLA versus } \\
0.5 \mathrm{~g} / \mathrm{L} \\
p\end{array}$} & \multirow{2}{*}{$\begin{array}{l}\text { PLA versus } \\
0.8 \mathrm{~g} / \mathrm{L} \\
p\end{array}$} \\
\hline & & & & & & & & & \\
\hline \multicolumn{10}{|l|}{ Critical Tracking Test } \\
\hline Lambda (rad/s) & $3.77(0.12)$ & $3.59(0.14)$ & $3.69(0.13)$ & $3.46(0.13)$ & 5.40 & $<0.01$ & $<0.05$ & 0.24 & $<0.001$ \\
\hline \multicolumn{10}{|l|}{ Divided Attention Test } \\
\hline Average error (mm) & $15.2(0.7)$ & $16.0(0.7)$ & $15.0(0.7)$ & $17.0(0.8)$ & 2.70 & 0.07 & 0.18 & 0.73 & $<0.05$ \\
\hline $\mathrm{RT}(\mathrm{ms})$ & $1,873(64.0)$ & $1,996(79.1)$ & $1,988(62.1)$ & $2,082(64.1)$ & 5.71 & $<0.01$ & $<0.05$ & $<0.01$ & 0.001 \\
\hline \multicolumn{10}{|l|}{ Psychomotor Vigilance Test } \\
\hline 1/RT (ms) & $4.05(0.1)$ & $3.96(0.1)$ & $3.91(0.1)$ & $3.75(0.1)$ & 5.74 & $<0.01$ & 0.14 & $<0.01$ & 0.001 \\
\hline $\mathrm{RT}(\mathrm{ms})$ & $261(6.6)$ & $268(9.0)$ & $275(9.3)$ & $286(7.9)$ & 6.49 & $<0.01$ & 0.23 & 0.01 & $<0.001$ \\
\hline \multicolumn{10}{|c|}{ Digit Symbol Substitution Test } \\
\hline Correct responses & $99.2(3.2)$ & $100.8(2.7)$ & $97.8(3.0)$ & $93.3(2.2)$ & 11.12 & $<0.001$ & 0.57 & 0.49 & $<0.01$ \\
\hline \multicolumn{10}{|l|}{ Attention Network Test } \\
\hline Overall RT (ms) & $468(12.5)$ & $470(11.1)$ & $473(13.3)$ & $498(12.1)$ & 9.93 & $<0.001$ & 0.74 & 0.45 & 0.001 \\
\hline Alerting effect (ms) & $63.8(8.2)$ & $53.6(5.6)$ & $67.0(8.5)$ & $75.7(8.0)$ & 2.25 & 0.11 & 0.22 & 0.72 & 0.27 \\
\hline Orienting effect (ms) & $32.1(4.8)$ & $32.4(3.8)$ & $27.1(4.4)$ & $31.9(5.1)$ & 0.45 & 0.72 & 0.95 & 0.35 & 0.98 \\
\hline Conflict effect (ms) & $77.8(8.4)$ & $80.2(8.1)$ & $86.3(8.6)$ & $98.9(8.5)$ & 2.24 & 0.11 & 0.64 & 0.42 & 0.07 \\
\hline \multicolumn{10}{|l|}{ Concept Shifting Test } \\
\hline RT CST-A (s) & $20.1(0.69)$ & $22.5(0.85)$ & $20.6(071)$ & $20.4(0.88)$ & 3.04 & 0.05 & 0.02 & 0.47 & 0.69 \\
\hline RT CST-B (s) & $24.1(0.77)$ & $23.7(0.95)$ & $23.4(0.81)$ & $23.6(0.80)$ & 0.22 & 0.88 & 0.70 & 0.40 & 0.64 \\
\hline RT CST-C (s) & $28.1(1.08)$ & $27.8(1.19)$ & $26.7(1.11)$ & $27.8(1.31)$ & 0.39 & 0.76 & 0.79 & 0.32 & 0.86 \\
\hline Interference $\left(\mathrm{CST}_{\mathrm{i}}\right)$ & $28.1(4.8)$ & $21.3(4.9)$ & $22.5(4.8)$ & $27.2(5.1)$ & 0.43 & 0.74 & 0.36 & 0.47 & 0.89 \\
\hline \multicolumn{10}{|l|}{ Digit Span Test } \\
\hline Forward-correct & $8.1(0.5)$ & $8.6(0.4)$ & $8.5(0.4)$ & $7.9(0.4)$ & 2.49 & 0.09 & 0.09 & 0.33 & 0.58 \\
\hline Backward-correct & $8.8(0.4)$ & $8.5(0.5)$ & $8.5(0.5)$ & $8.0(0.4)$ & 1.76 & 0.19 & 0.32 & 0.41 & $<0.05$ \\
\hline \multicolumn{10}{|l|}{ Balance Test } \\
\hline A95- eyes open $(\mathrm{cm})$ & $0.09(0.1)$ & $0.28(0.1)$ & $0.54(0.1)$ & $1.04(0.1)$ & 14.12 & $<0.001$ & 0.07 & 0.001 & $<0.001$ \\
\hline A95 - eyes closed $(\mathrm{cm})$ & $0.50(0.1)$ & $0.64(0.1)$ & $0.87(0.1)$ & $1.18(0.2)$ & 6.53 & $<0.01$ & 0.37 & 0.001 & $<0.01$ \\
\hline \multicolumn{10}{|c|}{ Subjective evaluations } \\
\hline \multicolumn{10}{|l|}{ Drunkenness } \\
\hline Before tests & $8.3(2.1)$ & $28.8(4.2)$ & $39.3(4.5)$ & $51.3(4.0)$ & 28.49 & $<0.001$ & $<0.001$ & $<0.001$ & $<0.001$ \\
\hline After tests & $10.0(2.0)$ & $27.5(4.0)$ & $34.8(3.7)$ & $45.6(4.2)$ & 20.77 & $<0.001$ & 0.001 & $<0.001$ & $<0.001$ \\
\hline Alertness & $69.3(3.2)$ & $64.3(3.6)$ & $65.6(3.6)$ & $56.1(4.0)$ & 11.86 & $<0.001$ & 0.09 & 0.23 & 0.001 \\
\hline Contentedness & $79.2(2.3)$ & $79.5(2.3)$ & $80.5(2.5)$ & $81.0(2.3)$ & 0.83 & 0.49 & 0.83 & 0.29 & 0.15 \\
\hline Calmness & $79.6(2.7)$ & $76.3(3.2)$ & $76.0(3.4)$ & $77.1(2.6)$ & 1.37 & 0.28 & 0.13 & 0.11 & 0.30 \\
\hline
\end{tabular}

$R T$ reaction time

found for subjective contentedness and calmness. The answer to the question which $\mathrm{BAC}$ was aimed for was indicated correctly on $56 \%$ of the occasions.

\section{Comparison of performance measures}

A summary of the mean difference scores with $95 \%$ confidence intervals, mean placebo-normalized $z$-scores, and Dunlap's effect sizes (ES) is shown in Table 2.
Effect sizes and $z$-scores show that tasks and parameters differ in sensitivity to the effects of alcohol. The largest effects were found on postural balance (ES=1.50 and 0.96 , for eyes open and eyes closed, respectively), inverse reaction time in the PVT $(\mathrm{ES}=0.70)$, and reaction time in the DAT $(\mathrm{ES}=0.65)$ at a BAC of $0.8 \mathrm{~g} / \mathrm{L}$. Of these tests, only the reaction time in the DAT showed a significant effect of the lowest BAC (i.e., $0.2 \mathrm{~g} / \mathrm{L}$ ) with an ES of 0.34. All three tests show strong dose effects of alcohol, which are moderate to large for a BAC of $0.5 \mathrm{~g} / \mathrm{L}$ and small to moderate for a BAC of $0.2 \mathrm{~g} / \mathrm{L}$ (see Fig. 3). 


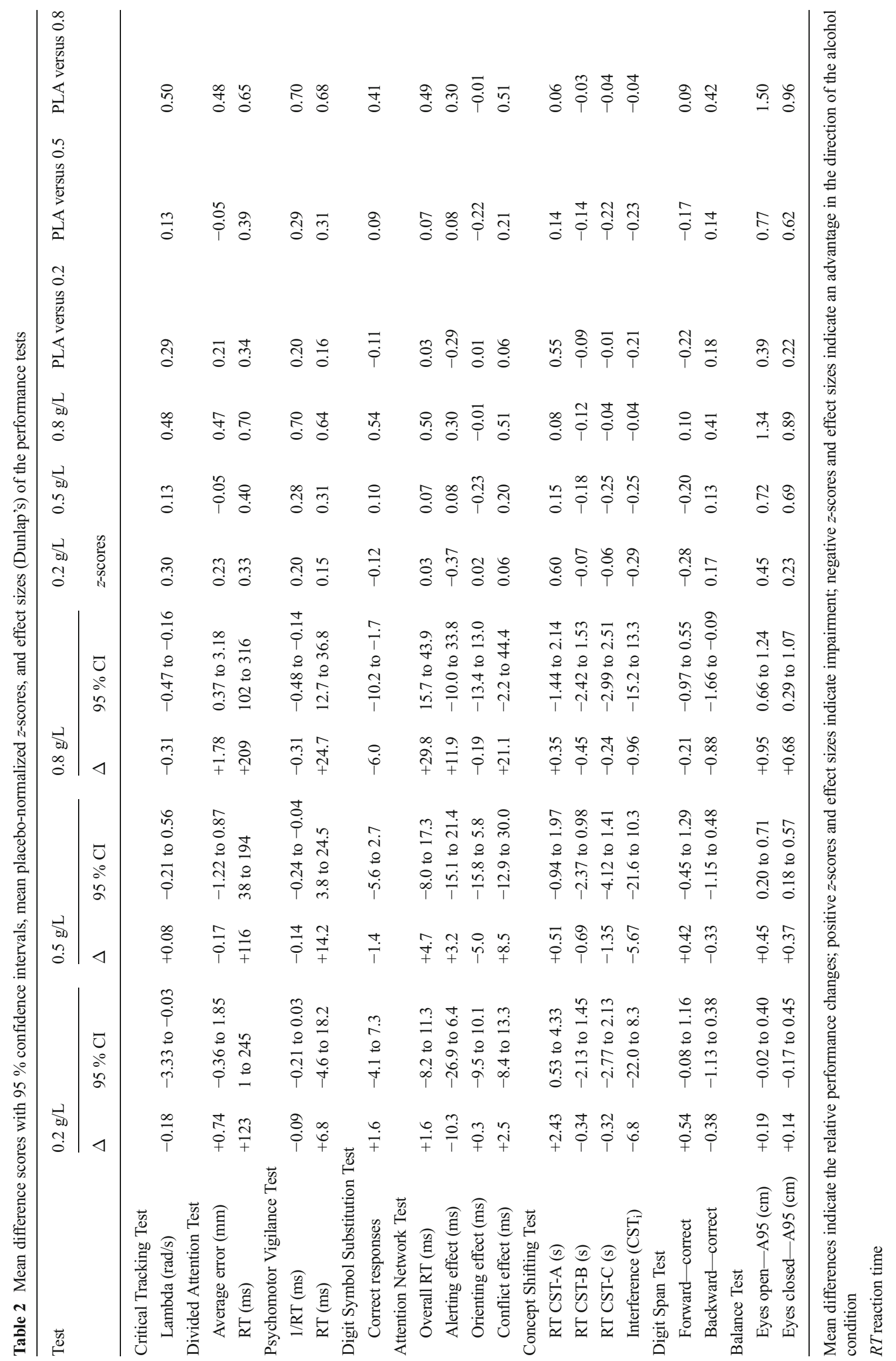


Fig. 3 Mean baseline normalized performance of BACs $0.2,0.5$, and $0.8 \mathrm{~g} / \mathrm{L}$ compared with placebo across dependent variables of the Critical Tracking Test, Divided Attention Test, Psychomotor Vigilance Test, and Attention Network Test. ${ }^{*} p<0.05$, $* * p<0.01, * * * p<0.001$. Error bars indicate the standard error of the mean
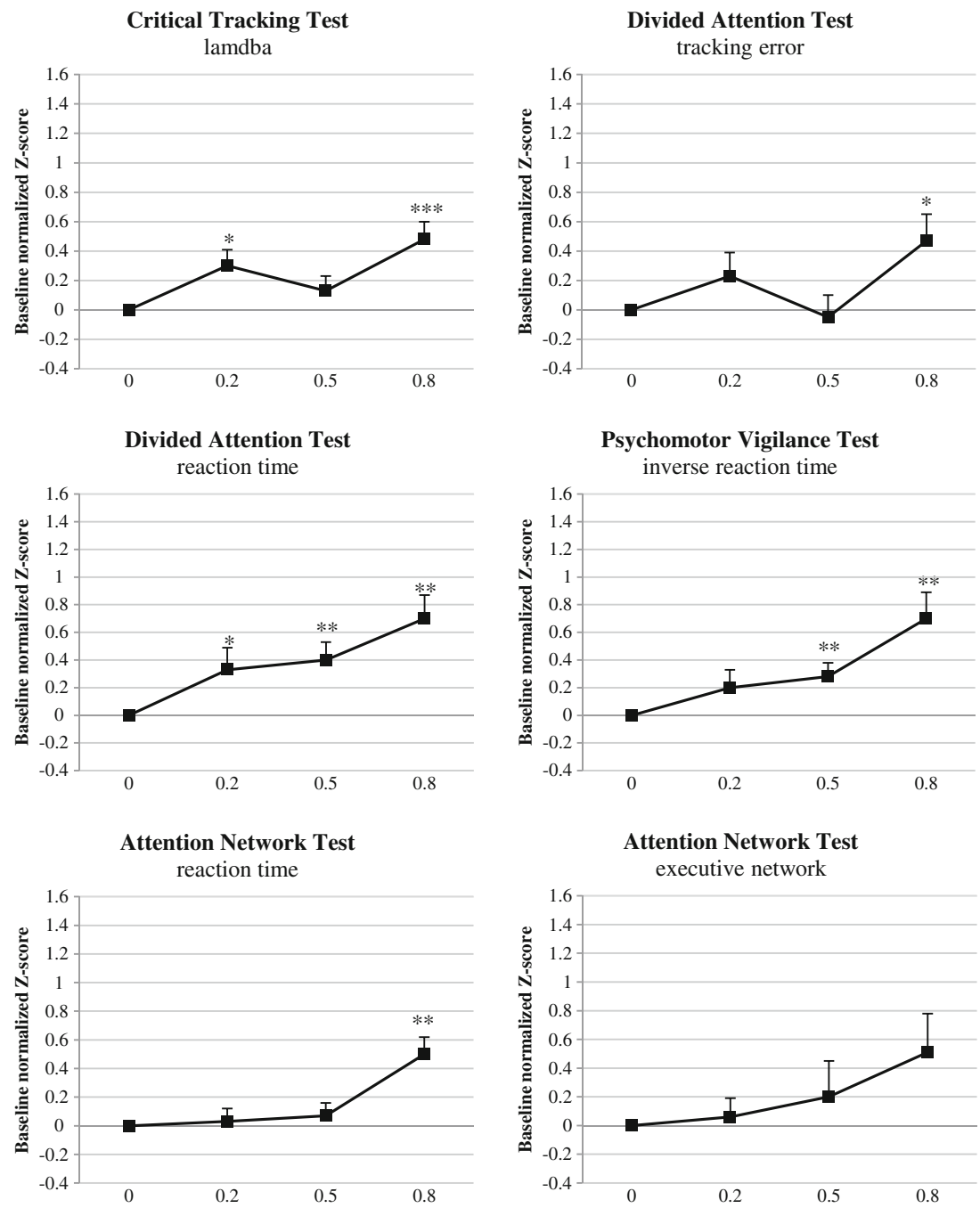

Performance in other tests showed less or no consistent dose-dependent effects of alcohol. Performance in the DSST and ANT is only impaired at a BAC of $0.8 \mathrm{~g} / \mathrm{L}$, but not by alcohol at a BAC of $0.5 \mathrm{~g} / \mathrm{L}$ or less. Performance in the CTT is impaired but does not show a consistent dose-dependent increase in the effect (see Fig. 3). Concept Shifting Test and Digit Span Test performance showed hardly any impairment (see Fig. 4).

\section{Discussion}

The aim of this study was to determine which performance tests could be useful to measure drug-induced impairment as an initial screening tool. This was examined by assessing their ability to detect the effects of various doses of alcohol resulting in BACs between 0.0 and $0.8 \mathrm{~g} / \mathrm{L}$. Eight tests were included measuring various skills related to driving, such as psychomotor speed (CTT, ANT, PVT, DSST, DAT), divided attention (DAT), sustained attention (PVT), spatial attention
(ANT), executive attention (ANT, CST), memory span (DST), and postural balance (PBT). The results showed that tasks and parameters varied in their sensitivity to the effects of alcohol.

All tests except the DST and CST showed statistically significant effects of alcohol intoxication. In terms of effects sizes, the largest and strongest dose-dependent effects of alcohol were found on performance in the PBT, PVT, and DAT. Only these tests showed significant impairment at a BAC of $0.5 \mathrm{~g} / \mathrm{L}$, the clinically relevant cutoff point as it is the legal limit for driving under the influence in most countries. Effect sizes for reaction time in the DAT and PVT were moderate (i.e., 0.39 and 0.29 , respectively) at a BAC of $0.5 \mathrm{~g} / \mathrm{L}$ and large (i.e., 0.65 and 0.70 ) at a BAC of $0.8 \mathrm{~g} / \mathrm{L}$. At the PBT with eyes open, a large effect size (i.e., 0.77) was found between placebo and a BAC of $0.5 \mathrm{~g} / \mathrm{L}$ and a very large effect size (i.e., 1.50) between placebo and a BAC of $0.8 \mathrm{~g} / \mathrm{L}$.

Most of the findings of the present study regarding the effects of alcohol on performance tests are in line with previous studies. Several studies support our finding that 
Fig. 4 Mean baseline normalized performance of BACs $0.2,0.5$, and $0.8 \mathrm{~g} / \mathrm{L}$ compared with placebo across dependent variables of the Digit Symbol Substitution Test, Concept Shifting Test, Digit Span Test, and Postural Balance Test. $* p<0.05$, $* * p<0.01, * * * p<0.001$. Error bars indicate the standard error of the mean
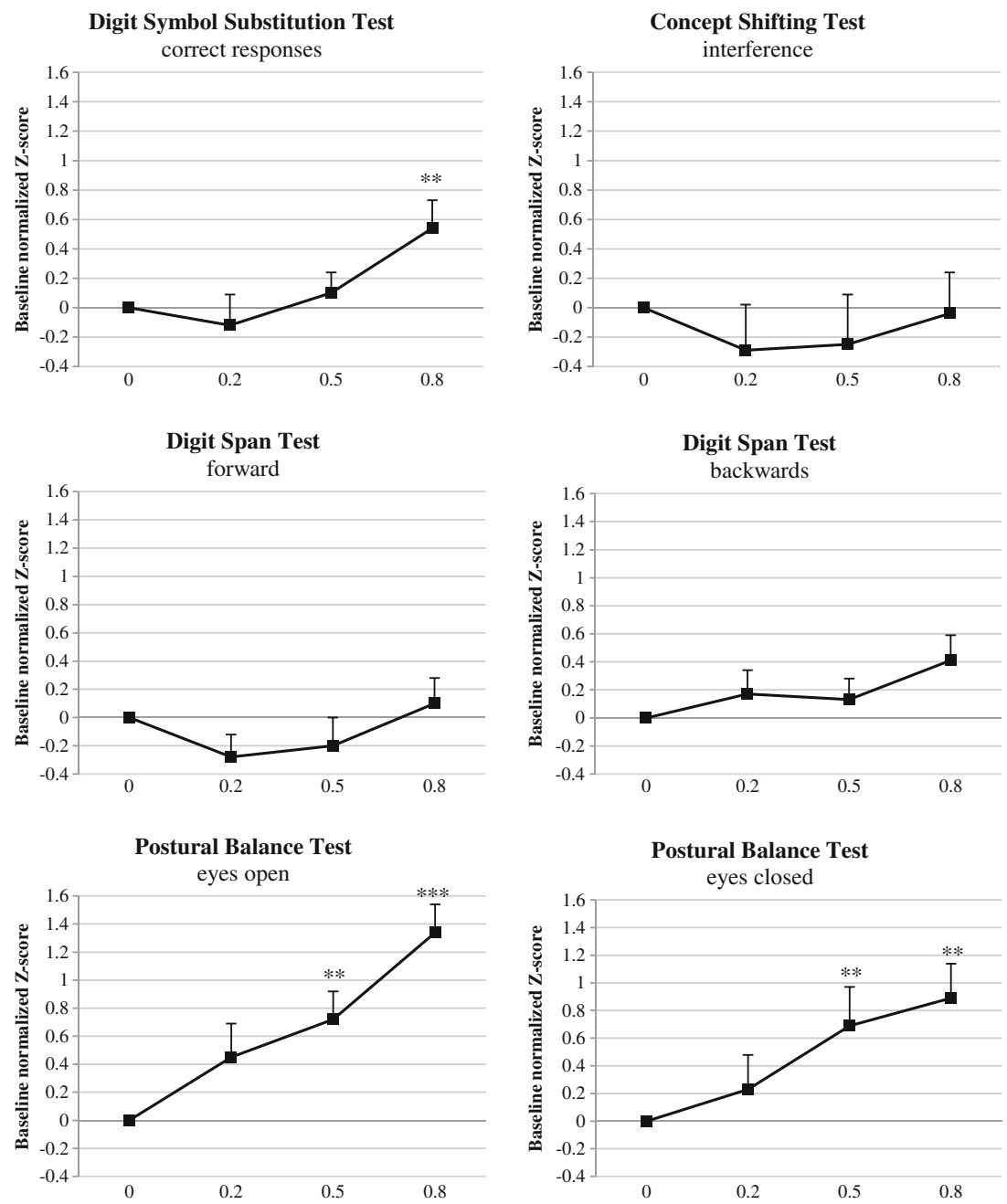

performance in the DAT, PVT and PBT is sensitive to low or moderate BACs (e.g., Evans and Levin, 2003, 2004; Howard et al. 2007; Leung et al. 2012; McCaul et al. 2000; Moskowitz and Robinson 1988; Moskowitz and Florentino 2000; Ogden and Moskowitz 2004; Roehrs et al. 2003). Furthermore, the failure of the CST to show any effects of alcohol is in line with recent findings that performance in a similar test (i.e., TMT part B) was only impaired at a very high BAC (i.e., $1.2 \mathrm{~g} / \mathrm{L}$ ), but not at lower BACs (i.e., 0.5 and $0.8 \mathrm{~g} / \mathrm{L}$ ) as used in the present study (Dry et al. 2012). Finally, our finding that the DSST shows impairment at a BAC of $0.8 \mathrm{~g} / \mathrm{L}$, but not below is in line with most previous studies. All studies have shown impairment at BACs of $0.8 \mathrm{~g} / \mathrm{L}$ or more, but results are not consistent at BACs between 0.4 and $0.6 \mathrm{~g} / \mathrm{L}$ ( Brasser et al. 2004; Brumback et al. 2007; Dumont et al., 2008; Evans and Levin 2003, 2004; Holdstock and de Wit 2001; King and Byars 2004; McCaul et al. 2000).

Regarding the CTT in the present study, impairment was found at a BAC of 0.2 and $0.8 \mathrm{~g} / \mathrm{L}$, but not at a BAC of $0.5 \mathrm{~g} / \mathrm{L}$. The failure of the CTT to show impairment at a BAC of 0.5 $\mathrm{g} / \mathrm{L}$ was unexpected. Several studies found impaired tracking performance at BACs ranging from 0.4 to $0.6 \mathrm{~g} / \mathrm{L}$ (Kuypers et al. 2006; Ramaekers et al. 2011b; Vermeeren and O'Hanlon 1998; Vermeeren et al. 2002). Only one study did not find impairment at a BAC of $0.64 \mathrm{~g} / \mathrm{L}$ (Simons et al. 2012). Even though participants were extensively trained in the current study, a learning effect could have occurred in participants who completed the $0.5 \mathrm{~g} / \mathrm{L}$ condition at the end of the second testing day. Based on previous findings, the CTT should indicate impairment at a BAC of $0.5 \mathrm{~g} / \mathrm{L}$, and therefore, this test should not be excluded as a test for initial screening. However, quantifying drug effects comparable to various BACs according to the present study should be done with caution, as no alcohol dose-dependent curve at the CTT was found in the present study.

The results of this study help further research to quantify drug effects. For example, the hypnotics gaboxadol $(15 \mathrm{mg})$ and zolpidem $(10 \mathrm{mg})$ taken in the middle of the night were found to increase reaction time in the DAT the next morning on average by $184 \mathrm{~ms}$ (Leufkens et al. 2009). These effects are comparable to the effects of a BAC of $0.8 \mathrm{~g} / \mathrm{L}$ on the same test in the present study. In contrast, zopiclone $(7.5 \mathrm{mg})$ taken at 
bedtime in the same study, increased next day reaction time in the DAT on average by $123 \mathrm{~ms}$, which is comparable to a BAC of $0.5 \mathrm{~g} / \mathrm{L}$ or lower according to the present study. Another study found a reaction time increase of $95 \mathrm{~ms}$ at the PVT for partial sleep deprivation compared with placebo, which is comparable to a BAC higher than $0.8 \mathrm{~g} / \mathrm{L}$ (Bosker et al. 2010).

One of the reasons why the PVT and DAT are more sensitive to impairment may be related to their longer duration. The duration of the PVT and DAT is 10 and $12 \mathrm{~min}$, respectively, whereas many other tests take no more than 2 or 3 min to complete (e.g., DST, CTT, CST, and DSST). Tests of longer duration may induce a vigilance decrement, which may enhance the impairing effects of sedative drugs. In shorter tests, a temporary increase of effort may compensate the impairing effects. Sensitivity of a test is however not only determined by its duration, as shown by the relatively small effects on performance in the longest test in the present study, the Attention Network Test, which has a duration of approximately $25 \mathrm{~min}$.

One limitation of the present study is that not all available tests measuring driving-related skills could be included to compare all these tests in one study. More studies are needed comparing other tests. Recently, one other study compared six tests using dose-related effects of alcohol (Dry et al. 2012). Based on strenghts of dose-dependent effects and effect sizes, the authors concluded that the Inspection Time test (measuring information processing speed), the Self-Ordered Pointing Task (measuring working memory) and the Sustained Attention to Response Task (measuring response inhibition and cognitive flexibility) were better suited to detect impairing effects of alcohol than the TMT, the Useful Field of View test, and a problem solving test.

Furthermore, the question remains how valid laboratory tests are to assess the domains of driving as proposed by several researchers. According to Walsh et al. (2008), three core levels of behavior should be measured to predict crash risks: (1) automative behavior, (2) control behavior, and (3) executive planning behavior. Furthermore, five essential driving ability domains were indicated: (1) alertness/arousal, (2) attention and processing speed, (3) reaction time/psychomotor functions, (4) sensory-perceptual functioning, and (5) executive functions (Kay and Logan 2011). It could be argued that the DAT is a relatively complex task incorporating all aspects, whereas the PVT is a relatively simple task which may be considered to be less sensitive to deficits in executive functioning. When using the PVT, an additional test for executive function deficits may be needed to cover the most relevant domains for driving. The validity of the PBT is less clear; it is not known whether the PBT is a valid measure of actual driving and whether it can predict actual driving performance. To predict actual driving impairment, the CTT and DAT have been found to moderately predict performance at the on-theroad driving test (Ramaekers 2003; Verster and Roth 2012).
Another aspect is that effects of sedative drugs or sedative conditions (e.g., sleep deprivation) can be quantified comparable to a particular BAC. Although there are many different drugs with differing mechanisms of action, one of the most common drug effects relevant for potential driving impairment is sedation or drowsiness, which is usually associated with slowing of responses and attentional deficits. It should however be noted that sedative drugs, sleep deprivation, and alcohol can have qualitatively different effects, as has been found previously (e.g., Kleykamp et al. 2010; Tiplady et al. 2003). We are currently exploring the differential effects of sleep deprivation and sedative drugs on tests measuring driving-related skills.

In conclusion, the preferable tests for initial screening are the DAT and the PVT, as these tests were most sensitive to the impairing effects of alcohol and being considerably valid in assessing potential driving impairment because of sedation or drowsiness.

Acknowledgments The authors thank Peter van Mulken and Joyce Weisser for their contribution to this study.

Conflict of interest The authors declare no conflicts of interest.

Open Access This article is distributed under the terms of the Creative Commons Attribution License which permits any use, distribution, and reproduction in any medium, provided the original author(s) and the source are credited.

\section{References}

Basner M, Dinges DF (2011) Maximizing sensitivity of the psychomotor vigilance test (PVT) to sleep loss. Sleep 34(5):581-591

Bond A, Lader M (1974) The use of analogue scales in rating subjective feelings. Br J Med Psychol 47(3):211-218

Borkenstein F, Crowther RF, Shumate RP, Zeil WB, Zylman R (1964) The role of the drinking driver in traffic accidents. Indiana University, Bloomington

Bosker WM, Kuypers KP, Conen S, Ramaekers JG (2010) Dose-related effects of MDMA on psychomotor function and mood before, during, and after a night of sleep loss. Psychopharmacology 209(1):69-76

Boyle J, Danjou P, Alexander R, Calder N, Gargano C, Agrawal N, Murphy MG (2009) Tolerability, pharmacokinetics and night-time effects on postural sway and critical flicker fusion of gaboxadol and zolpidem in elderly subjects. Br J Clin Pharmacol 67(2):180-190

Brasser SM, McCaul ME, Houtsmuller EJ (2004) Alcohol effects during acamprosate treatment: a dose-response study in humans. Alcoholism: Clin Exp Res 28(7):1074-1083

Brumback T, Cao D, King A (2007) Effects of alcohol on psychomotor performance and perceived impairment in heavy binge social drinkers. Drug and Alcohol Depend 91(1):10-17

Clark P, Blissmer B, Greene G (2011) Maintaining exercise and healthful eating in older adults: the SENIOR project II: study design and methodology. Contemp Clin Trials 32:129-139

Dinges D, Powell J (1985) Microcomputer analyses of performance on a portable, simple visual RT task during sustained operations. Behav Res Methods 17(6):652-655 
Doran S (2001) Sustained attention performance during sleep deprivation: evidence of state instability. Archives Italiennes de Biologie 139(3):253-267

Dry MJ, Burns NR, Nettelbeck T, Farquharson AL, White JM (2012) Dose-related effects of alcohol on cognitive functioning. PloS One 7(11):e50977

Dumont GJH, Wezenberg E, Valkenberg MMGJ, De Jong CAJ, Buitelaar JK, Van Gerven JMA, Verkes RJ (2008) Acute neuropsychological effects of MDMA and ethanol (co-) administration in healthy volunteers. Psychopharmacology 197(3):465-474

Dunlap WP, Cortina JM, Vaslow JB, Burke MJ (1996) Meta-analysis of experiments with matched groups or repeated measures designs. Psychol Methods 1(2):170-177

Evans SM, Levin FR (2003) Response to alcohol in females with a paternal history of alcoholism. Psychopharmacology 169(1):10-20

Evans SM, Levin FR (2004) Differential response to alcohol in light and moderate female social drinkers. Behav Pharmacol 15(3):167-181

Fan J, McCandliss BD, Sommer T, Raz A, Posner MI (2002) Testing the efficiency and independence of attentional networks. J Cogn Neurosci 14(3):340-347

Falleti MG, Maruff P, Collie A, Darby DG, McStephen M (2003) Qualitative similarities in cognitive impairment associated with $24 \mathrm{~h}$ of sustained wakefulness and a blood alcohol concentration of 005\%. J Sleep Res 12(4):265-274

Fillmore M, Carscadden J, Vogel-Sprott M (1998) Alcohol, cognitive impairment and expectancies. J Stud Alcohol Drugs 59(2):174

González-Wilhelm L (2007) Prevalence of alcohol and illicit drugs in blood specimens from drivers involved in traffic law offenses. Systematic review of cross-sectional studies. Traffic Inj Prev 8(2): 189-198

Greenblatt DJ, Legangneux E, Harmatz JS, Weinling E, Freeman J, Rice K, Zammit GK (2006) Dynamics and kinetics of a modified-release formulation of zolpidem: comparison with immediate-release standard zolpidem and placebo. J Clin Pharmacol 46(12):1469-1480

Holdstock L, Wit H (2001) Individual differences in responses to ethanol and d-amphetamine: a within-subject study. Alcohol: Clin Exp Res 25(4):540-548

Houwing S, Hagenzieker M, Mathijssen R (2011) Prevalence of alcohol and other psychoactive substances in drivers in general traffic, part I: general results. Deliverable 223, DRUID (Driving under the Influence of Drugs, Alcohol and Medicines) 6th framework programme. Available at http://www.druid-project.eu

Howard ME, Jackson ML, Kennedy GA, Swann P, Barnes M, Pierce RJ (2007) The interactive effects of extended wakefulness and lowdose alcohol on simulated driving and vigilance. Sleep 30(10): $1334-1340$

International Council on Alcohol Drugs and Traffic Safety (ICADTS) (1999) Guidelines on experimental studies undertaken to determine a medicinal drug's effect on driving or skills related to driving. Bundes Anstalt fuer Strassenwesen (BASt), Cologne, p 1-13

Jewett ME, Dijk DJ, Kronauer RE, Dinges DF (1999) Dose-response relationship between sleep duration and human psychomotor vigilance and subjective alertness. Sleep 22(2):171-179

Jex HR, McDonnell JD, Phatak AV (1966) A “critical” tracking task for man-machine research related to the operator's effective delay time. I. Theory and experiments with a first-order divergent controlled element. NASA CR-616. NASA CR, 1-105

Kay G, Logan B (2011) Drugged driving expert panel report: a consensus protocol for assessing the potential of drugs to impair driving. National Highway Traffic Safety Administration, Washington, DC

King AC, Byars JA (2004) Alcohol-induced performance impairment in heavy episodic and light social drinkers. J Stud on Alcohol Drugs 65(1):27-36

Kleykamp BA, Griffiths RR, Mintzer MZ (2010) Dose effects of triazolam and alcohol on cognitive performance in healthy volunteers. Exp Clin Psychopharmacol 18(1):1
Krüger HP (1993) Effects of low alcohol dosages: a review of the literature. In: Utzelmann HD, Berghaus G, Kroj G (eds) Alcohol, drugs and traffic safety-T'92. TÜV Rheinland, Cologne, pp 763778

Kuypers KP, Samyn N, Ramaekers JG (2006) MDMA and alcohol effects, combined and alone, on objective and subjective measures of actual driving performance and psychomotor function. Psychopharmacology 187(4):467-475

Lacey JH, Kelley-Baker T, Furr-Holden D, Brainard K, Moore C (2009) Pilot test of new roadside survey methodology for impaired driving (No HS-810 704). National Highway Traffic Safety Administration, Washington, DC

Leufkens TRM, Lund JS, Vermeeren A (2009) Highway driving performance and cognitive functioning the morning after bedtime and middle-of-the-night use of gaboxadol, zopiclone and zolpidem. J Sleep Res 18(4):387-396

Leung S, Croft RJ, Jackson ML, Howard ME, McKenzie RJ (2012) A comparison of the effect of mobile phone use and alcohol consumption on driving simulation performance. Traffic Inj Prev 13(6):566574

Louwerens J, Gloerich A, de Vries G, Brookhuis K, O’Hanlon J (1987) The relationship between drivers' blood alcohol concentration (BAC) and actual driving performance during high speed travel. In: Noordzij PC, Roszbach R (eds) Alcohol Drugs Traffic Safety T86. Elsevier, Amsterdam, pp 183-186

McCaul ME, Wand GS, Eissenberg T, Rohde CA, Cheskin LJ (2000) Naltrexone alters subjective and psychomotor responses to alcohol in heavy drinking subjects. Neuropsychopharmacology 22(5):480 492

McLeod DR, Griffiths RR, Bigelow GE, Yingling J (1982) An automated version of the digit symbol substitution test (DSST). Behav Res Methods Instrum 14(5):463-466

Mets MAJ, Volkerts ER, Olivier B, Verster JC (2010) Effect of hypnotic drugs on body balance and standing steadiness. Sleep Med Rev 14(4):259-267

Mets MAJ, de Vries JM, de Senerpont Domis LM, Volkerts ER, Olivier B, Verster JC (2011) Next-day effects of ramelteon $(8 \mathrm{mg})$, zopiclone $(75 \mathrm{mg})$, and placebo on highway driving performance, memory functioning, psychomotor performance, and mood in healthy adult subjects. Sleep 34(10):1327-1334

Michon JA (1989) Explanatory pitfalls and rule-based driver models. Accid; Anal Prev 21(4):341-353

Moskowitz H (1973) Laboratory studies of the effects of alcohol on some variables related to driving. J Saf Res 1973(5):185-199

Moskowitz H, Robinson C (1988) Driving-related skills in impairment at low blood alcohol levels. Alcohol, Drugs Traffic Saf 86:79-86

Moskowitz H, Florentino D (2000) A review of the literature on the effects of low doses of alcohol on driving-related skills (No HS809 028). National Highway Traffic Safety Administration, Washington, DC

Ogden EJD, Moskowitz H (2004) Effects of alcohol and other drugs on driver performance. Traffic Inj Prev 5(3):185-198

O'Hanlon JF (1984) Driving performance under the influence of drugs: rationale for, and application of, a new test. Br J Clin Pharmacol 18(Suppl 1):121-129

O'Hanlon JF, Haak TW, Blaauw GJ, Riemersma JB (1982) Diazepam impairs lateral position control in highway driving. Science 217(4554):79-81

Ramaekers JG (2003) Antidepressants and driver impairment: empirical evidence from a standard on-the-road test. J Clin Psychiatr 64(1): 20-29

Ramaekers JG, Conen S, de Kam PJ, Braat S, Peeters P, Theunissen EL, Ivgy-May N (2011a) Residual effects of esmirtazapine on actual driving performance: overall findings and an exploratory analysis into the role of CYP2D6 phenotype. Psychopharmacology 215(2): 321-332 
Ramaekers JG, Theunissen EL, de Brouwer M, Toennes SW, Moeller MR, Kauert G (2011b) Tolerance and cross-tolerance to neurocognitive effects of THC and alcohol in heavy cannabis users. Psychopharmacology 214(2):391-401

Riedel WJ, Mehta MA, Unema PJ (2006) Human cognition assessment in drug research. Curr Pharm Des 12(20):2525-2539

Robbe H, O'Hanlon J (1995) Acute and subchronic effects of paroxetine 20 and $40 \mathrm{mg}$ on actual driving, psychomotor performance and subjective assessments in healthy volunteers. Eur Neuropsychopharmacol 5:35-42

Roehrs T, Burduvali E, Bonahoom A, Drake C, Roth T (2003) Ethanol and sleep loss: a "dose" comparison of impairing effects. Sleep 26(8):981-985

Roth T, Mayleben D, Corser BC, Singh NN (2008) Daytime pharmacodynamic and pharmacokinetic evaluation of low-dose sublingual transmucosal zolpidem hemitartrate. Hum Psychopharmacol 23(1): $13-20$

Schnabel E, Hargutt V, Krüger H (2010) Meta-analysis of empirical studies concerning the effects of alcohol on safe driving. Deliverable 112a, DRUID (Driving under the Influence of Drugs, Alcohol and Medicines) 6th framework programme. Available at http://www.druid-project.eu/

Seppala T, Linnoila M, Mattila M (1979) Drugs, alcohol and driving. Drugs 17(5):389

Simons R, Martens M, Ramaekers J, Krul A, Klöpping-Ketelaars I, Skopp G (2012) Effects of dexamphetamine with and without alcohol on simulated driving. Psychopharmacology 222(3):391399

Silva MT, Laks J, Engelhardt E (2009) Neuropsychological tests and driving in dementia: a review of the recent literature. Revista da Associação Médica Brasileira 55(4):484

Stuster J, Burns M, Büx P (1998) Validation of the standardized field sobriety test battery at BACs below 0.10 percent. National Highway Traffic Safety Administration, Washington, DC

Tiplady B, Hiroz J, Holmes L, Drummond G (2003) Errors in performance testing: a comparison of ethanol and temazepam. J Psychopharmacol 17(1):41-49

Van der Elst WMP, Van Boxtel M, Van Breukelen GJ, Jolles J (2006) The Concept Shifting Test: adult normative data. Psychol Assess 18: 424-432

Vermeeren A, De Gier JJ, O'Hanlon JF (1994) Methodological guidelines for experimental research on medicinal drugs affecting driving performance: an international expert survey. J Traffic Med 22(4): $173-174$

Vermeeren A, O'Hanlon JF (1998) Fexofenadine's effects, alone and with alcohol, on actual driving and psychomotor performance. J Allergy Clin Immunol 101(3):306-311

Vermeeren A, Riedel WJ, van Boxtel MP, Darwish M, Paty I, Patat A (2002) Differential residual effects of zaleplon and zopiclone on actual driving: a comparison with a low dose of alcohol. Sleep 25(2): 224-231

Verster JC, Roth T (2011) Standard operation procedures for conducting the on-the-road driving test, and measurement of the standard deviation of lateral position (SDLP). Int J Gen Med 4:359-371

Verster JC, Roth T (2012) Predicting psychopharmacological drug effects on actual driving performance (SDLP) from psychometric tests measuring driving-related skills. Psychopharmacology 220(2): 293-301

Verstraete, A, Knoche, A, Jantos, R, and Skopp, G (2011) Per se limitsmethods of defining cut off values for zero tolerance. Deliverable 142, DRUID (Driving under the Influence of Drugs, Alcohol and Medicines) 6th framework programme. Available at http://www. druid-project.eu/

Vingilis E, Macdonald S (2002) Review: drugs and traffic collisions. Traffic Inj Prev 3(1):1-11

Walsh JM, Verstraete AG, Huestis MA, Mørland J (2008) Guidelines for research on drugged driving. Addiction 103(8):1258-1268

Walsh JM, de Gier JJ, Christopherson AS, Verstraete AG (2004) Drugs and driving. Traffic Inj Prev 5(3):241-253

Watson P, Watson I, Batt R (1981) Prediction of blood alcohol concentrations in human subjects; updating the Widmark equation. J Stud Alcohol drugs 42(07):547

Weaver B, Bédard M, McAuliffe J, Parkkari M (2009) Using the Attention Network Test to predict driving test scores. Acc; Anal Prev 41(1):76-83

Wechsler D (1997) WMS-III: Wechsler memory scale administration and scoring manual. Psychological Corporation, San Antonio

Widmark EM (1932) Die theoretischen Grundlagen und die praktische Verwendbarkeit der gerichtlich-medizinischen Alkoholbestimmung. Urban \& Schwarzenberg, Berlin

Zador PL, Krawchuk SA, Voas RB (2000) Alcohol-related relative risk of driver fatalities and driver involvement in fatal crashes in relation to driver age and gender: an update using 1996 data. J Stud Alcohol drugs 61(3):387 